\title{
Turn Based Strategy Game "Perang Komando" Dengan Metode Finite State Machine Pada Karakter Musuh
}

\author{
Wennedy Surya Pratama ${ }^{1)}$, Amak Yunus ${ }^{2)}$, Wasum ${ }^{3)}$ \\ ${ }^{1,2,3)}$ Program Studi Teknik Informatika, Universitas Kanjuruhan Malang, Indonesia \\ wennedy.suryadev@gmail.com ${ }^{1)}$,amakyunus@unikama.ac.id ${ }^{2)}$,dwasum@yahoo.co.id ${ }^{3)}$
}

\begin{abstract}
Games are an alternative means of entertainment media that has been chosen in the era of globalization like today. In an offline game, especially a single player mode where players have to fight enemies controlled by computers or artificial intelligence. One of the artificial intelligence researchers chose to study was the finite state machine. The problem is how to apply this artificial intelligence to enemy characters in turn-based strategy games. Before implementing the game development must be done, the research method used is the waterfall approach method. During game development, researchers get the result that the enemy unit is able to check the conditions that have been determined and make decisions according to these conditions.
\end{abstract}

Keywords - Turn Based Strategy; Game; Finite State Machine; Decision Making; Artificial Intelligence

\begin{abstract}
Abstrak. Game adalah alternatif sarana media hiburan yang banyak dipilih pada era globalisasi seperti saat ini. Di dalam sebuah game offline khususnya mode single player dimana pemain harus melawan musuh yang dikendalikan oleh komputer atau kecerdasan buatan. Salah satu kecerdasan buatan yang peneliti pilih untuk diteliti adalah finite state machine. Yang menjadi permasalahannya ialah bagaimana menerapkan kecerdasan buatan ini kepada karakter musuh dalam game ber-genre turn based strategy. Sebelum menerapkannya pengembangan game tersebut harus dilakukan, metode penelitian yang digunakan adalah metode pendekatan waterfall. Selama pengembangan game, peneliti mendapatkan hasil bahwa unit musuh mampu memeriksa kondisi yang sudah ditentukan dan mengambil keputusan sesuai dengan kondisi-kondisi tersebut.
\end{abstract}

Kata Kunci - Turn Based Strategy; Permainan; Finite State Machine; Pengambilan Keputusan; Kecerdasan Buatan

\section{PENDAHULUAN}

Perkembangan teknologi di era globalisasi ini melaju dengan pesat, salah satunya adalah perkembangan di bidang hiburan game. Menurut data yang tercatat per tanggal 13 Februari 2018, jumlah game yang terdapat dalam Steam (distributor permainan digital) sebanyak 20.775 buah dengan rata - rata 137 game muncul setiap bulannya, dengan jumlah pengguna yang sedang bermain dengan jumlah puncak 17.076.022 pengguna pada malam hari.

Data tersebut menyimpulkan bahwa banyak individu yang mencari hiburan dengan cara bermain game untuk melepaskan penat dari aktivitas sehari - harinya. Game memiliki banyak jenis / genre yang saat ini berkembang, diantaranya adalah Turn Based Strategy (TBS). Genre ini sudah terkenal sejak lama dan masih banyak beredar hingga sekarang. Ini dibuktikan dengan jumlah game ber-genre turn based strategy yang beredar di Steam dengan total sebanyak 441 buah per tanggal 13 Februari 2018.

Setiap game terdiri dari satu atau lebih genre yang ada di dalamnya. Sampai saat ini, genre game yang terkenal adalah Action Game, Adventure Game, dan Multiplayer Online Battle Arena (MOBA). Padahal faktanya jumlah genre game yang ada sampai saat ini berjumlah 20 jenis.

Salah satu genre game yang populer zaman dulu adalah genre Turn Based Strategy (TBS). Walau sekarang jarang diminati, game dengan genre TBS memiliki kelebihan dibandingkan dengan genre lainnya yaitu tidak terikat dengan waktu di dalam permainan. Pemain diberikan waktu yang tidak terhingga sehingga pemain dapat dengan bebas mengatur strategi untuk mengalahkan musuh. Selain itu, pemain dapat bermain diiringi dengan melakukan aktivitas yang lainnya karena waktu yang diberikan tidak terbatas.

Umumnya dalam sebuah game, terdapat dua buah mode permainan yaitu: mode single player dan multiplayer. Untuk mode single player, pemain berhadapan dengan musuh yang dikendalikan oleh komputer. Di sini peran kecerdasan buatan (Artificial Intelligence) diperlukan karena komputer perlu melakukan pengambilan keputusan dari semua tindakan yang dilakukan oleh pemain.

Salah satu kecerdasan buatan dalam game adalah Finite State Machine (FSM). Finite State Machine dapat dikategorikan sebagai salah satu model kecerdasan buatan yang sederhana dan paling banyak digunakan dalam game. Sebuah state machine terdiri dari beberapa states yang terhubung dalam grafik serta transisi perpindahan dari satu state ke state lainnya. Yang menjadi permasalahan adalah bagaimana menerapkan Finite State Machine pada karakter 
musuh dengan menentukan kondisi yang tepat untuk merubah suatu state ke state lain yang sesuai agar mampu merespon tindakan pemain.

Berdasarkan uraian masalah diatas, peneliti tertarik mengambil judul "Turn Based Strategy "Perang Komando" Dengan Metode Finite State Machine Pada Karakter Musuh" untuk memberikan pilihan lebih banyak kepada karakter musuh dalam membuat decision making. Setiap pengambilan keputusan ditentukan oleh dua variabel yaitu banyaknya darah pemain dan radius antara pemain dan karakter musuh dalam game.

\section{METODE}

Penelitian adalah suatu penyelidikan atau suatu bentuk percobaan pengujian dalam mencari fakta yang diperlukan untuk menemukan jawaban yang ilmiah dalam suatu masalah. Metode penelitian yang digunakan dalam pengembangan ini adalah metode pendekatan waterfall.

\section{A. Prosedur Penelitian Pengembangan}

Dalam melakukan sebuah penelitian, ada prosedur atau tahapan yang harus dilakukan untuk memenuhi tujuan awal dari penelitian yang sedang dilakukan. Untuk pengembangan game Perang Komando ini, peneliti menggunakan metode pendekatan waterfall yang meliputi beberapa tahap dan definisi pengerjaan setiap tahapnya.

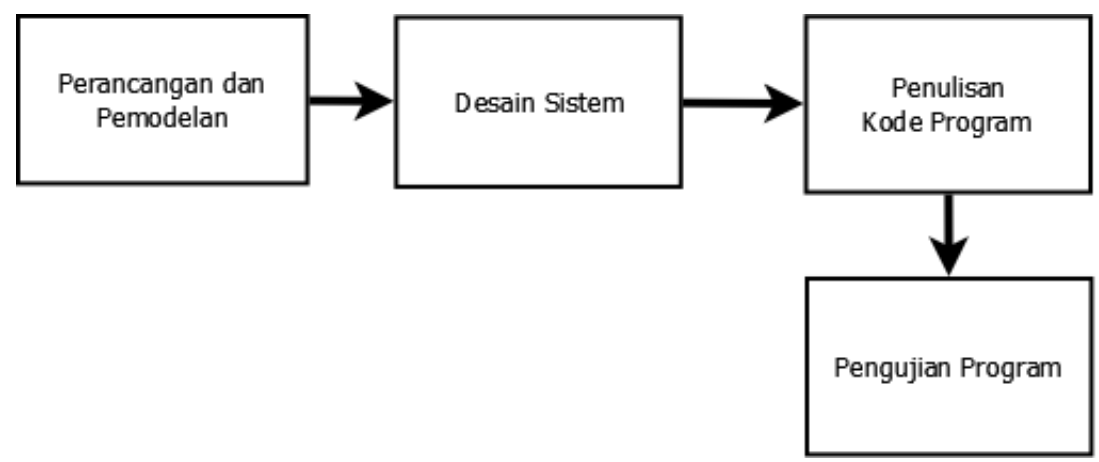

Gambar 1. Metode pengembangan pendekatan waterfall

Perancangan dan pemodelan adalah tahap penerjemahan dari data yang dianalisis ke dalam bentuk yang mudah dimengerti oleh pengguna. Perancangan sendiri dalam pengembangan game Perang Komando merupakan pembuatan konsep game seperti alur permainan, aturan permainan dan kondisi permainan.

Desain Sistem adalah tahap menggambarkan perancangan user interface (UI), baik itu menerangkan menggunakan huruf ataupun menggunakan alur diagram yang menggambarkan jalannya perangkat lunak.

Penulisan Kode Program adalah tahap penerjemahan data atau pemecahan masalah yang telah dirancang ke dalam bahasa pemrograman tertentu. Dalam pengembangan game ini bahasa pemrograman yang digunakan adalah C\# dan menggunakan editor Mono Develop.

Pengujian Program adalah tahap pengujian terhadap perangkat lunak yang akan dibangun. Bentuk pengujian yang digunakan adalah Uji Skenario yang mana berguna untuk memeriksa apakah metode finite state machine yang diterapkan sudah berjalan dengan baik atau belum.

\section{B. Uji Coba Produk}

Pada bagian uji coba produk, peneliti melakukan uji skenario dari beberapa kemungkinan dan kondisi yang muncul dalam permainan. Dengan mengimplementasikan metode finite state machine kepada setiap unit musuh yang ada di masing-masing level, akan muncul sebuah pengambilan keputusan yang diambil oleh unit musuh. Uji skenario ini bertujuan untuk mengetahui apakah keputusan yang diambil oleh unit musuh sesuai dengan kondisi atau variabel yang sudah ditentukan.

\section{Waktu dan Tempat Penelitian}

Penelitian ini akan dilakukan di Laboratorium Multi Media Universitas Kanjuruhan Malang yang bertempat dan memiliki alamat di Jl. S. Supriadi No. 48, Bandungrejosari, Sukun, Kota Malang, Jawa Timur 65148. Sedangkan untuk waktu penelitian akan dilaksanakan pada bulan November 2018 sampai dengan bulan Januari 2019. 


\section{HASIL DAN PEMBAHASAN}

Pengujian implementasi metode finite state machine pada karakter musuh dalam game Perang Komando versi beta ini menggunakan uji skenario. Untuk uji skenario, posisi setiap unit pemain maupun musuh dan kode setiap unit bisa dilihat pada Gambar 2.

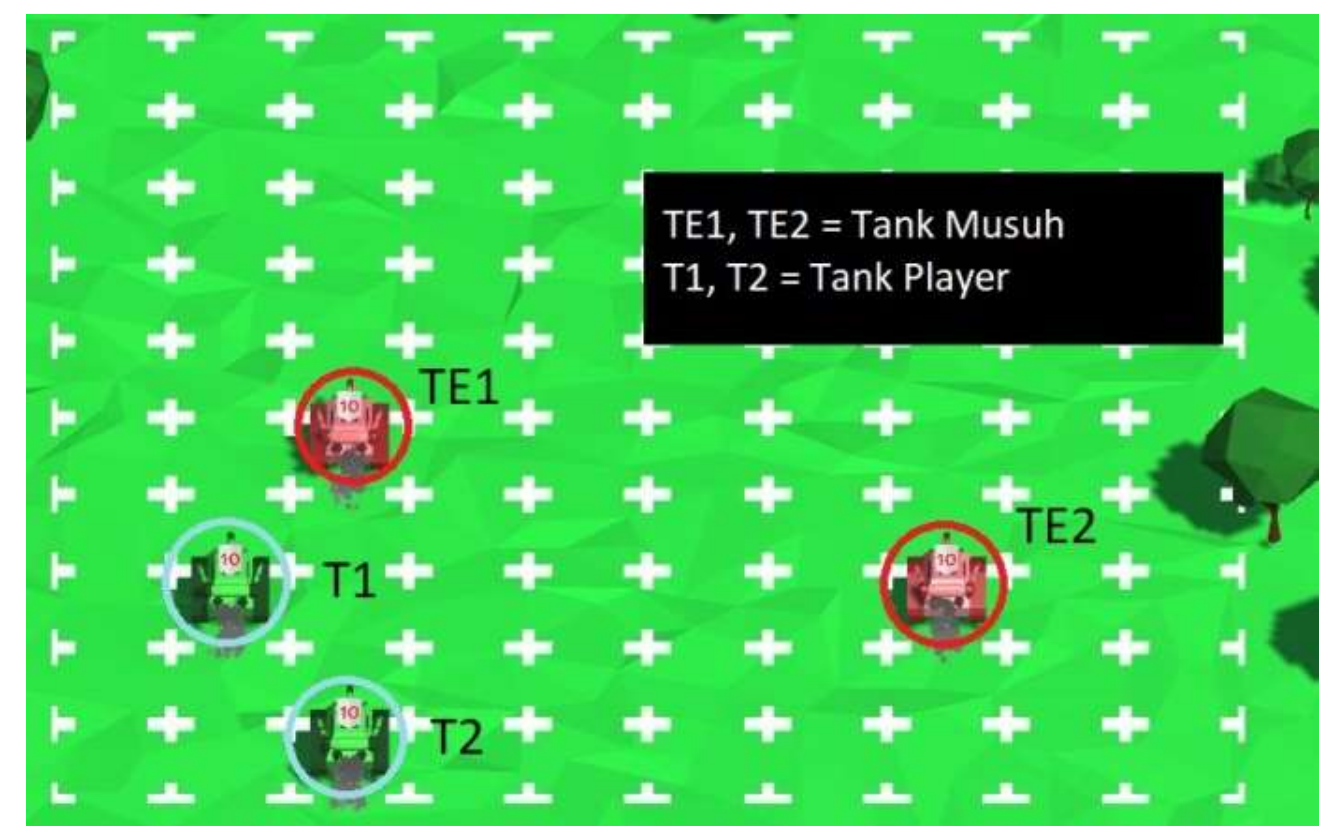

Gambar 2. Posisi serta keterangan unit pemain dan musuh.

Bila diasumsikan semua tile yang bisa dituju unit T1 adalah anggota himpunan A. maka anggota himpunan A adalah $=\{(1,5),(1,6),(1,7),(1,8),(1,9),(1,10),(2,4),(2,5),(2,6),(2,7),(2,8),(2,9),(2,10),(3,5),(3,7),(3,9),(4,6)$, $(4,7),(4,8),(4,9),(4,10),(5,7),(5,8),(5,9),(6,8)\}$, seperti yang terlihat pada Gambar 3.

Gambar 3. Semua kemungkinan tujuan pemain bergerak untuk T1

Lalu semua tile pemeriksaan pemain terdekat unit TE1 adalah anggota himpunan B dan unit TE2 adalah anggota himpunan $\mathrm{C}$, maka anggota himpunan $\mathrm{B}=\{(1,5),(1,6),(1,7),(2,4),(2,5),(2,6),(2,7),(3,3),(3,4),(3,5),(3,7),(3,8)$, $(3,9),(4,4),(4,5),(4,6),(4,7),(4,8),(5,5),(5,6),(5,7),(6,6)\}$ dan anggota himpunan $\mathrm{C}=\{(5,8),(6,7),(6,8),(6,9)$, $(7,6),(7,7),(7,8),(7,9),(7,10),(8,5),(8,6),(8,7),(8,9),(8,10),(9,6),(9,7),(9,8),(9,9),(9,10),(10,7),(10,8),(10,9)$ \}. Seperti yang terlihat pada Gambar 4 .

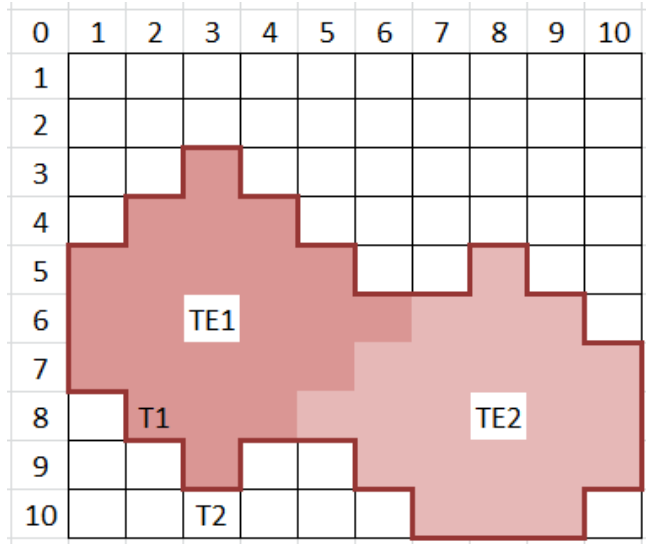

Gambar 4. Radius Pemeriksaan Pemain Terdekat Unit Musuh 
Apabila kita menggabungkan Gambar 3 dan 4 maka akan didapatkan hasil seperti pada Gambar 5.

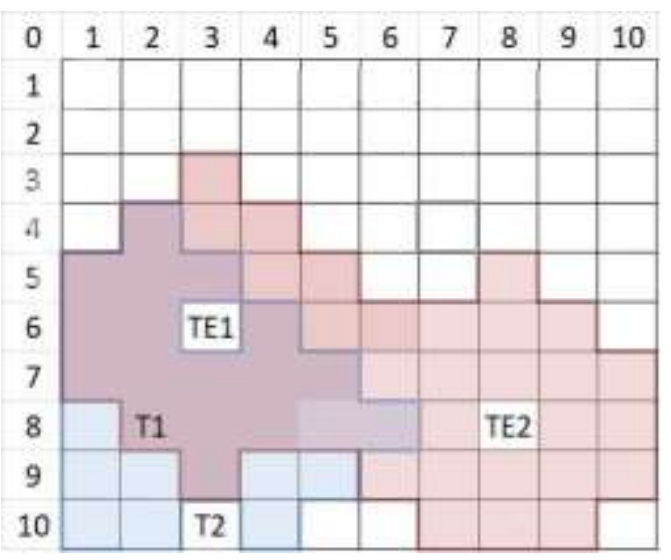

Gambar 5. Gabungan himpunan tile unit T1, TE1 dan TE2.

Setelah dilakukan pengujian maka dapat diambil hasil seperti pada Tabel 1.

Tabel 1. Hasil Pengujian Skenario

\begin{tabular}{|c|c|c|c|c|c|c|c|}
\hline \multirow{3}{*}{$\begin{array}{c}\text { Nama } \\
\text { Unit }\end{array}$} & \multirow{2}{*}{\multicolumn{2}{|c|}{$\begin{array}{c}\text { Koordina } \\
\mathrm{t}\end{array}$}} & \multicolumn{5}{|c|}{ Unit Musuh } \\
\hline & & & \multirow{2}{*}{$\begin{array}{c}\text { Kondisi } \\
\text { Darah } \\
(\mathrm{HP})\end{array}$} & \multicolumn{2}{|c|}{ TE1 } & \multicolumn{2}{|c|}{ TE2 } \\
\hline & $\mathrm{x} 1$ & $\mathrm{y} 1$ & & Keputusan & Tile Tujuan & Keputusan & Tile Tujuan \\
\hline \multirow{12}{*}{$\mathrm{T} 1$} & 1 & 8 & $\mathrm{HP} \geq 5$ & Diam & - & Diam & - \\
\hline & 2 & 9 & $\mathrm{HP} \geq 5$ & Diam & - & Diam & - \\
\hline & 1 & 8 & $\mathrm{HP}<5$ & Diam & - & Diam & - \\
\hline & 2 & 9 & $\mathrm{HP}<5$ & Diam & - & Diam & - \\
\hline & 1 & 7 & $\mathrm{HP} \geq 5$ & Menyerang & - & Diam & - \\
\hline & 4 & 6 & $\mathrm{HP} \geq 5$ & Menyerang & - & Diam & - \\
\hline & 5 & 8 & $\mathrm{HP} \geq 5$ & Diam & - & Menyerang & - \\
\hline & 6 & 8 & $\mathrm{HP} \geq 5$ & Diam & - & Menyerang & - \\
\hline & 1 & 7 & $\mathrm{HP}<5$ & Menjauh & $(6,5)$ & Diam & - \\
\hline & 4 & 6 & $\mathrm{HP}<5$ & Menjauh & $(1,8)$ & Diam & - \\
\hline & 5 & 8 & $\mathrm{HP}<5$ & Diam & - & Menjauh & $(10,9)$ \\
\hline & 6 & 8 & $\mathrm{HP}<5$ & Diam & - & Menjauh & $(10,9)$ \\
\hline
\end{tabular}

Maka dapat disimpulkan dengan melihat Tabel 1 bahwa semua koordinat tujuan unit pemain yang merupakan anggota himpunan A yang tidak termasuk anggota himpunan B maupun C maka unit musuh akan mengambil keputusan untuk diam terlepas dari kondisi $\mathrm{HP} \geq 5$ atau $\mathrm{HP}<5$. Namun apabila koordinat tujuan adalah $\mathrm{A} \cap \mathrm{B}$ dengan kondisi unit musuh TE1 HP $\geq 5$ maka akan menyerang T1, sedangkan untuk $\mathrm{A} \cap \mathrm{C}$ dengan kondisi yang sama maka yang menyerang adalah unit musuh TE2. Lalu untuk kondisi HP $<5$ bila unit pemain target tujuannya adalah anggota himpunan B maka unit musuh TE1 yang menjauh, untuk himpunan C unit musuh TE2 yang menjauh, dan untuk tujuan anggota himpunan $\mathrm{B} \cap \mathrm{C}$ maka keduanya akan menjauh.

Maka pengambilan keputusan yang diambil oleh unit musuh sesuai dengan metode finite state machine yang terlihat seperti pada Gambar 6. 


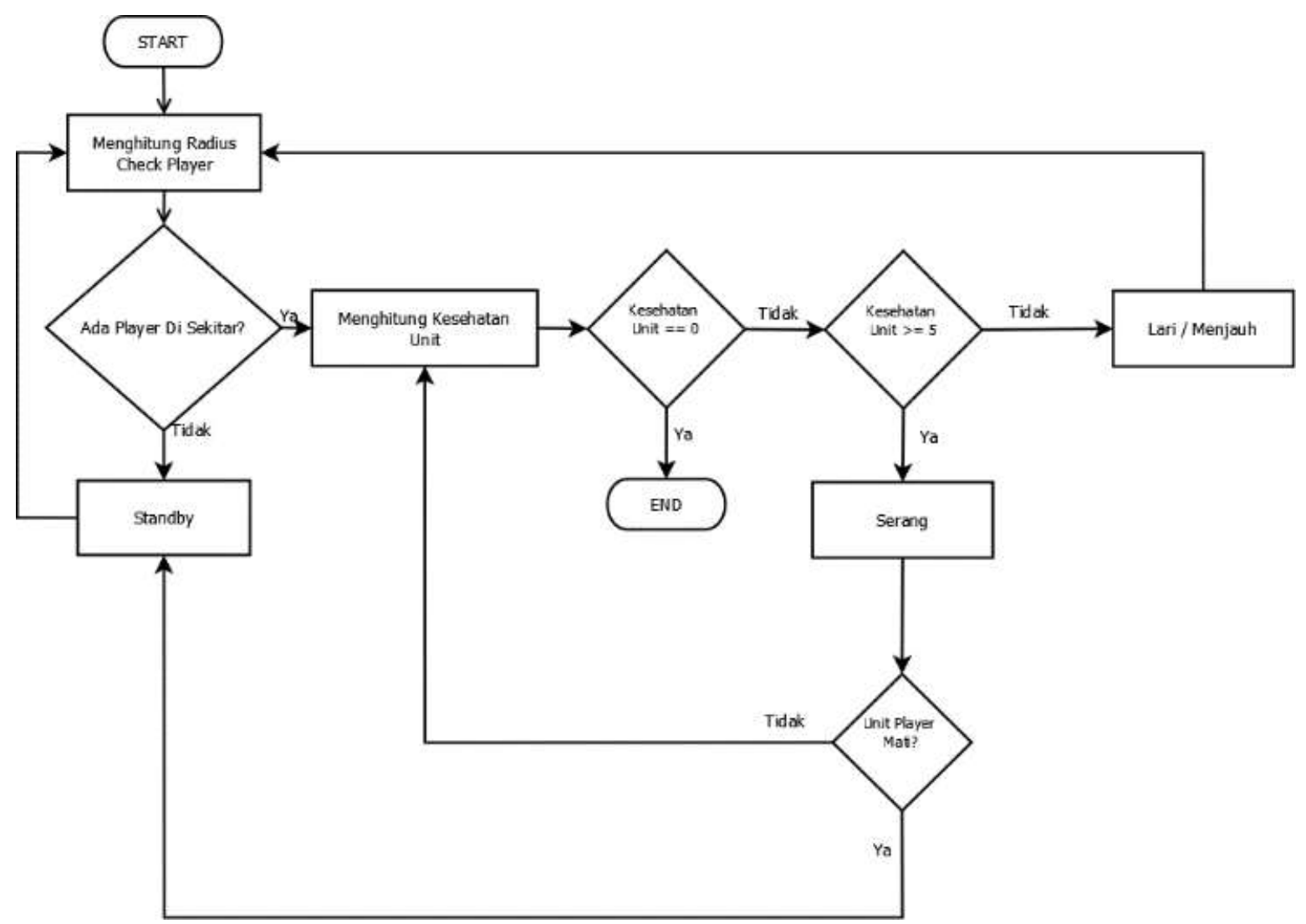

Gambar 6. Finite State Machine Pada Musuh

\section{KESIMPULAN}

Berdasarkan pembahasan pada Turn Based Strategy Game "Perang Komando" dengan Metode Finite State Machine Pada Karakter Musuh dapat disimpulkan bahwa pada game Perang Komando telah menghasilkan sebuah kecerdasan buatan yang mampu mengambil keputusan dalam bertindak sesuai dengan tindakan yang diambil oleh pemain. Beberapa pengambilan keputusan oleh musuh yaitu, unit musuh mengambil keputusan untuk diam saat unit pemain tidak berada dalam jarak tembak unit musuh dan health point unit musuh tidak kurang dari lima poin, unit mengambil keputusan untuk menyerang saat unit player berada dalam jarak serangan dan health point unit musuh lebih besar sama dengan lima poin, dan keputusan untuk bergerak menjauh ketika unit pemain mendekat dan health point yang dimiliki unit musuh kurang dari lima poin.

\section{UCAPAN TERIMA KASIH}

Terima kasih peneliti ucapkan atas semua pihak yang berperan penting dalam pelaksanaan penelitian ini khususnya admin Laboratorium Multimedia Universitas Kanjuruhan Malang yang telah memberi izin melakukan pelaksanaan penelitian ini.

\section{REFERENSI}

Caesar, Rio. (2015). Kajian Pustaka Perkembangan Genre Games dari Masa Ke Masa. Journal Of Animation and Games Studies, Vol.1 No. 2, Teknik Informatika. Universitas Atma Jaya Yogyakarta.

Galyonkin, Sergey. 2018. Overall Game Released In Months, (Online) (https://www.steamspy.com/year), diakses pada tanggal 13 Februari 2018. Pukul 00.55 WIB.

Kyaw, Peters, dan Swe, Thet Naing. (2013). Unity 4.x Game AI Programming. United Kingdom : Packt Publishing Ltd. 
Laaveri, Toni. (2017). Integrating AI For Turn-Based 4X Strategy Game. Helsinki Metropolia Unversity of Applied Sciences.

Liapis, Yannakakis dan Togelius, Julian. (2013). Generating Map Sketches For Strategy Games. Denmark : IT University of Copenhagen.

Marzial, Fadel dan Qamal. Mukti. (2017). Game RPG “The Royal Sword” Berbasis Desktop Dengan Menggunakan Metode Finite State Machine (FSM). Aceh : Universitas Malikussaleh Lhokseumawe.

McClarty, K. L., dkk, (2012). A Literature Review of Gaming in Education. The Assessment \& Information group of Pearson, dalam Pearson (http://www.pearsonassesments.com/research), diakses 15 Maret 2018.

Millington, Ian dan Funge, John. (2010). Artificial Intelligence for Games 2nd Edition. USA : Morgan Kaufmann Publisher. 